\title{
Optimal Configuration of Micro Power Supply for Hybrid AC/DC Micro-grid
}

\author{
Mingguang Zhang ${ }^{1,2,3}$ and Ruiyun Zhang ${ }^{1,2,3^{*}}$ \\ ${ }^{1}$ College of Electrical and Information Engineering, Lanzhou University of Technology, Lanzhou 730050, China \\ ${ }^{2}$ Key Laboratory of Gansu Advanced Control for Industrial Processes, Lanzhou University of Technology, Lanzhou 730050, \\ China \\ ${ }^{3}$ National Demonstration Center for Experimental Electrical and Control Engineering Education, Lanzhou University of \\ Technology, Lanzhou 730050, China \\ ${ }^{*}$ Corresponding author
}

\begin{abstract}
In the ac/dc hybrid micro-grid, the reasonable configuration of the micro power to improve power supply reliability and economy is the most important issue due to the types and combinations of distributed power sources are too many. The paper considers the power installation cost, the operation maintenance cost and the equipment replacement cost, as well as the loss of power supply probability and the excess energy ratio as the multi-objective function. The improved particle swarm optimization algorithm is used to optimize the micro power. Through matlab simulation verification, and the basic particle swarm optimization algorithm for comparative analysis. The results indicate that the improved particle swarm algorithm can effectively save the cost of the system and improve the operation efficiency of the ac/dc hybrid micro-grid.
\end{abstract}

Keywords—ac/dc hybrid micro-grid; improved particle swarm optimization algorithm; optimal configuration; loss of power supply probability

\section{INTRODUCTION}

In recent years, the hybrid micro-grid has attracted more and more attention with the continuous development of microgrid science and technology [1-3]. Because there are many kinds of distributed power supply in the ac/dc hybrid micro grid, it is very important for the system to adopt different micro-power combination mode for the stability, security and economic operation of the system. Not only the renewable energy can't be full used of, but also the power supply reliability can't be guaranteed if the capacity and the access type of the micro power are not well selected at the beginning of the construction. At the same time, the cost of the investment increases accompany with the increasing energy loss and the decreasing power quality. Therefore, it is significant to study the optimal configuration of the micro power supply [4-6].

At present, a large number of literatures have studied the optimal configuration of micro power supply in the micro-grid. In literature [7], the optimal configuration model is solved through the improved human worker ant colony algorithm, and the improved energy management strategy is put forward. Literature [8] adopts the improved invasion weeds optimization algorithm by considering the equipment investment cost, low carbon cost, parallel operation of electricity trading and other comprehensive economic cost as the objective function to realize the micro power optimal configuration. Literature [9] uses the hybrid quantum genetic algorithm comparing with the optimization results of common genetic algorithm. The results show that the improved algorithm has better effect. Literature [10] algorithm was optimized by using an improved biogeography, and the rationality of the configuration model was verified.

The paper mainly includes wind turbines, photovoltaic arrays, storage batteries, and establishes the corresponding model respectively [11-13]. The micro power supply in the ac/dc hybrid micro-grid is optimized by using the improved particle swarm optimization algorithm, and regarding the power installation, operation maintenance and equipment replacement costs, as well as the loss of power supply probability and the excess energy ratio as the multi-objective function while considering several constraints [14-15]. The simulation results show that the improved particle swarm optimization algorithm is more economical.

\section{The Power Model In The AC/DC Hybrid Micro- GRID CONTAINING WIND FARM AND PHOTOVOLTAIC}

\section{A. Wind Power Generation Probability Model}

The wind speed whose randomness is generally very high can be obtained by its probability distribution. The twoparameter Weibull distribution which has simple form can well fit the actual distribution of the wind speed from the perspective of probability and statistics. The formulation for the wind speed can be written as (1)

$$
f(v)=\left(\frac{k}{c}\right) \cdot\left(\frac{v}{c}\right)^{k-1} \cdot \exp \left[-\left(\frac{v}{c}\right)\right]^{k}
$$

Where $\mathrm{v}$ represents the wind speed, $\mathrm{c}$ is proportion parameter while its value is greater than 1 . Similarly, $\mathrm{k}$ is the shape parameter while its value is greater than 1 . These two parameters in the distribution can be received by the average value $\bar{v}$ and the standard deviation of the wind speed. As presented in Eq. (2) 


$$
k=\left(\frac{\sigma}{\bar{v}}\right)^{-1.086} ; \mathrm{c}=\frac{\bar{v}}{\Gamma(1+1 / k)} .
$$

Where $\Gamma$ is the Gamma function.

There are three very important parameters in the operation of the wind turbine, which are the rated wind speed, the start wind speed and the off wind speed. The output characteristic of the wind turbine is generally described by piecewise function. Abundant experiments show that the power characteristic equation of the wind turbine is presented in Eq. (3)

$$
P_{W T}=\left\{\begin{array}{l}
0,0 \leq v \leq v_{c i} \\
P_{r} \cdot \frac{v-v_{c i}}{v_{r}-v_{c i}}, v_{c i} \leq v \leq v_{r} \\
P_{r}, v_{r} \leq v \leq v_{c o} \\
0, v_{c o} \leq v
\end{array} .\right.
$$

Where $\mathrm{v}$ is the actual wind speed, $v_{c i}$ is the start wind speed, $3 \mathrm{~m} / \mathrm{s} . v_{r}$ is the rated wind speed, $11 \mathrm{~m} / \mathrm{s}$. $v_{c o}$ is the off wind speed of the wind turbine in above formula, $25 \mathrm{~m} / \mathrm{s}$. $P_{r}$ shows the rated power $30 \mathrm{~kW}, P_{W T}$ represents the actual power of the wind turbine when the wind speed is $\mathrm{v}$ [16].

\section{B. Photovoltaic Power Generation Probability Model}

The solar illumination intensity is random. Studies have shown that, the intensity of illumination is considered to be a probability density function approximately obeying the Beta distribution in a certain amount of time. The formulation can be written as

$$
f(G(t))=\frac{\Gamma(\alpha+\beta)}{\Gamma(\alpha) \Gamma(\beta)}\left(\frac{G(t)}{G_{\max }}\right)^{\alpha-1}\left(1-\frac{G(t)}{G_{\max }}\right)^{\beta-1}
$$

where $G(t)$ and $G_{\max }$ indicate the actual light intensity and maximum illumination intensity respectively during the period. $\alpha$ and $\beta$ all represent the key shape parameters in the Beta distribution which are calculated through the average value $\bar{v}$ and the standard deviation of the solar illumination intensity in a certain amount of time. $\Gamma$ is the Gamma function.

$$
\alpha=\mu .\left[\frac{\mu(1-\mu)}{\sigma^{2}}-1\right] ; \beta=(1-\mu) \cdot\left[\frac{\mu(1-\mu)}{\sigma^{2}}-1\right]
$$

The model of the photovoltaic power output power $P_{P V}$ is given in Eq. (6)

$$
P_{P V}=f_{P V} P_{\text {rated }} \frac{A}{A_{S}}\left[1+\alpha_{p}\left(T-T_{S T C}\right)\right]
$$

Where $f_{P V}$ is the power reduction factor, $P_{\text {rated }}$ is rated power. $\mathrm{A}$ is the current actual radiation degree. $A_{S}$ is the irradiance under the standard test. $\alpha_{p}$ is the power temperature coefficient. $\mathrm{T}$ is the surface temperature of the current photovoltaic power generation system. $T_{S T C}$ is the system temperature under the standard test conditions.

\section{Energy Storage Device Model}

The working parameters of the energy storage device should be considered before using, while the state of charge shouled be predicted in advance. The charging and discharging power of the energy storage device is restrained in order that the service life of the energy storage device is extended.

Considering the state of charge, the battery is selected as the energy storage device. The formulation for the SOC can be written as (7)

$$
S O C=S O C_{0}+\frac{1}{C_{b a t}} \int_{t_{0}}^{t}\left(I_{b a t}-I_{\text {loss }}\right) d \tau
$$

Where $S O C_{0}$ represents the initial state of charge of the battery. $C_{b a t}$ is the rated capacity. $I_{b a t}$ is the actual charge and discharge current. When it is greater than 0 , the battery is charged, and less than 0 indicates the battery discharge. $I_{\text {loss }}$ is the battery loss response current.

\section{OPTIMIZED CONFIGURATION OF MICRO POWER SUPPLY}

\section{A. Objective Function}

The annualized cost of system is an important index of micro power optimization configuration. The paper chiefly establishes the optimal configuration model of the ac/dc hybrid micro-grid with wind turbines, photovoltaic arrays and storage batteries, and considers the power installation cost, the operation maintenance cost and the equipment replacement cost, as well as the loss of power supply probability and the excess energy ratio as the multi-objective function to make the annualized cost of system achieve the minimum.

- Power installation cost

The installation cost of the micro power supply $C_{C P i}$ is given in Eq. (8) 


$$
C_{C P i}=\frac{r(1+r)^{Y_{p}}}{(1+r)^{Y_{p}}-1} C_{T C P i}
$$

Where $Y_{P}$ is the full life cycle which is set to 20 years to simplify the calculation. $r$ is the discount rate set to $6.7 \%$.

- Operation maintenance.

The annual maintenance cost $C_{O M i}$ of micro power supply is directly proportional to the installed capacity $P_{i}$ of the unit.

$$
C_{O M i}=K_{O M i} P_{i}
$$

Where $K_{O M i}$ is the proportional coefficient of each micro power supply in the formulation (9).

- Equipment replacement cost

The equipment replacement cost $C_{R E P i}$ for micro power supply is shown in Eq. (10)

$$
C_{R E P i}=C_{T R E P} \frac{r}{(1+r)^{Y_{R E P}}-1} .
$$

Where $C_{T R E P}$ is the equipment replacement cost. $Y_{R E P}$ is the equipment replacement cycle life.

- Loss of power supply probability

The loss of power supply probability as a micro power grid reliability index is defined in Eq. (11)

$$
R_{L P S P}=\frac{\sum_{t=1}^{8760} L_{L P S P . t}}{8760} .
$$

Where $R_{L P S P}$ is the reliability index of the micro grid operation in the whole year. $L_{L P S P . t}$ is the lack of electrical marker in the system.

- $\quad$ Excess energy ratio

The energy excess ratio is defined as the excess energy of the system during the whole year of operation divided by the total demand energy of the system load. The formula can be written as (12)

$$
R_{E X C}=\sum_{t=1}^{8760} P_{E X C . t} / \sum_{t=1}^{8760} P_{L O A D . t}
$$

Where $R_{E X C}$ indicates the excess energy ratio. $P_{L O A D . t}$ is the total demand energy of the system.

The Loss of power supply probability and the excess energy ratio of the system will be included in the objective function of the paper. The formulation is in Eq. (13)

$$
\begin{aligned}
& \min F=\sum_{i=1}^{N}\left(C_{C P i}+C_{O M i}+C_{R E P i}\right) x_{i}+\gamma[\max (0, \\
& \left.\left.R_{L P S P}-R_{L P S P \text { max }}\right)\right]+\eta\left[\max \left(0, R_{E X C}-R_{E X C \text { max }}\right)\right]
\end{aligned}
$$

Where $x_{i}$ indicates the quantities of the power station. $R_{L P S P \text {.max }}$ is the maximum number of the loss of power supply probability of the system. $R_{E X C \text { max }}$ is the maximum number of the excess energy ratio which is set to $1 . \gamma$ and $\eta$ are all penalty factors. The annualized cost is in Eq. (14).

$$
A C S=\sum_{i=1}^{N}\left(C_{C P i}+C_{O M i}+C_{R E P i}\right) x_{i}
$$

\section{B. Constraint Conditions}

- Power output power constraint

For the i micro power supply, there is the formulation (15)

$$
P_{i} \leq p_{i} x_{i}
$$

Where $p_{i}$ indicates the single machine capacity quantity.

- $\quad$ State of charge of the battery

$$
S O C^{\min } \leq S O C \leq S O C^{\max }
$$

Where $S O C^{\text {max }}$ and $S O C^{\text {min }}$ are the maximum and the minimum capacity of the battery respectively in the formulation (16). The values are 1 and 0.2.

- Charge and discharge power constraints

$$
\left\{\begin{array}{l}
P_{+} \leq 0.2 E_{b a t} / \Delta t \\
P_{-} \leq 0.2 E_{b a t} / \Delta t
\end{array}\right.
$$

Where $E_{b a t}$ is the nominal capacity of the battery. $\Delta t$ is $1 \mathrm{~h}$. $P_{+}$and $P_{-}$are the charging and the discharging powers per hour in the formulation (17).

- Reliability constraint 


$$
\left\{\begin{array}{l}
R_{E X C} \leq R_{E X C \text { max }} \\
R_{L P S P} \leq R_{L P S P \text {.max }}
\end{array}\right.
$$

\section{IMPROVED PARTICLE SWARM OPTIMIZATION}

\section{A. Basic Particle Swarm Optimization}

The basic particle swarm optimization algorithm as one of the optimization algorithms uses each particle as a potential solution to the optimization problem [17]. It could update the location and the velocity of the particle by combining particles during each iteration. Each dimension is updated independently with other dimensions while the only connection between optimization problem space dimensions is introduced through the objective function. Therefore, every dimensional case can be analyzed without losing generality. The equation of the basic particle swarm optimization algorithm is shown in Eq. (19).

$$
\left\{\begin{array}{l}
v_{i}(t+1)=w \cdot v_{i}(t)+c_{1} \cdot r_{1} \cdot\left(p_{i}(t)-x_{i}(t)\right) \\
+c_{2} \cdot r_{2} \cdot\left(p_{g}(t)-x_{i}(t)\right) \\
x_{i}(t+1)=x_{i}(t)+v_{i}(t+1)
\end{array}\right.
$$

Where $\mathrm{w}$ is the inertia weight. $t$ is the number of iterations. $x_{i}$ is the particle position vector at the time iteration. $v_{i}$ is the particle velocity vector at the time iteration. $C_{1}$ and $C_{2}$ are accelerated constants. $r_{1}$ and $r_{2}$ are random values between 0 and 1.

\section{B. Improved Particle Swarm Optimization Algorithm Based on Genetic Crossing}

The basic particle swarm optimization algorithm is a common algorithm with a fast convergence. Because there are some disadvantages of the premature convergence and the local optimum, the convergence results are not reliable. In order to improve the algorithm, a variety of improved particle swarm optimization algorithms are proposed.

The improved particle swarm optimization algorithm based on genetic crossing adopts the cross-operation of the genetic algorithm. The cross-operation realizes the communication of information through the cross between the parent and the child. Then new individuals are created. The main idea is

First, the algorithm reserves half of the particles with high fitness value, so that they can go directly into the next generation, and replace the position and velocity vector of the half of the particles with the first half particles with high fitness. Then, the last half of the particles are paired randomly for cross-operation to generate new offspring. The number of the offspring is the same as that of the parent. The algorithm selects higher fitness half particles into the next generation through the comparison between the offspring and the parent again. By increasing the cross-operation in the search process, the diversity of particles is improved, and the convergence speed of the algorithm is accelerated.

$$
\begin{gathered}
\left\{\begin{array}{l}
c h \times 1=p b \times p \times 1+(1-p b) \times p \times 2 \\
\operatorname{ch} \times 2=p b \times p \times 2+(1-p b) \times p \times 1
\end{array}\right. \\
\left\{\begin{array}{l}
\operatorname{ch} v 1=\frac{p v 1+p v 2}{|p v 1+p v 2|} \times|p v 1| \\
\operatorname{ch} v 2=\frac{p v 1+p v 2}{|p v 1+p v 2|} \times|p v 2|
\end{array}\right.
\end{gathered}
$$

Where $c h x 1$ and $c h x 2$ are offspring's position. $p x 1$ and $p \times 2$ are locations of the fathers. chv1 and chv2 are offspring's velocities. $p v 1$ and $p v 2$ are velocities of the fathers. $p b$ is a random value between 0 and 1 .

\section{Flow Chart of Improved Particle Swarm Optimization Algorithm}

The improved particle swarm optimization algorithm increases the diversity of particles. The flow chart of the optimization is shown in Figure 1.

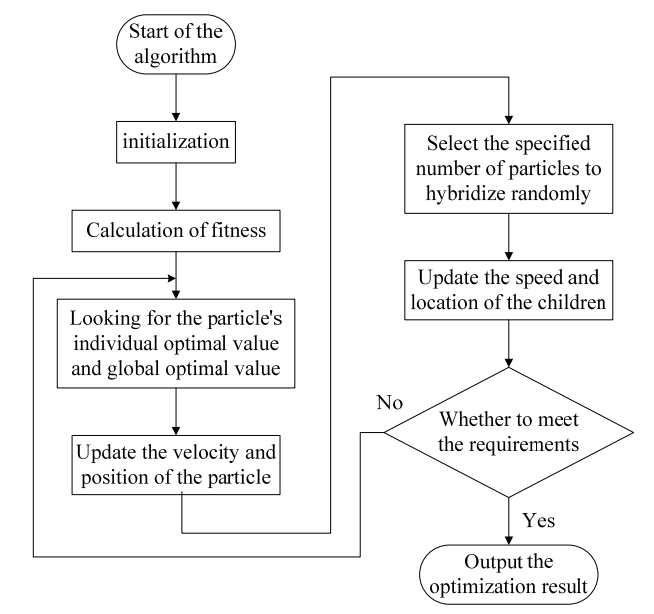

FIGURE I. THE FLOW CHART OF THE OPTIMIZATION

\section{CASE AnALysis}

Using the improved particle swarm optimization algorithm proposed in thispaper, the micro power optimization configuration of the typical ac/dc hybrid micro-grid system is carried out. Distributed powers used are wind turbines, photovoltaic arrays and storage batteries. Table 1 is the parameter table of the each unit cost data. 
TABle I. Parameter Table Of The Each Unit Cost Data

\begin{tabular}{|c|c|c|c|c|}
\hline $\begin{array}{c}\text { Micro } \\
\text { power }\end{array}$ & $\begin{array}{c}\text { power } \\
\text { installation }\end{array}$ & $\begin{array}{c}\text { operation } \\
\text { maintenance }\end{array}$ & $\begin{array}{c}\text { equipment } \\
\text { replacement }\end{array}$ & $\begin{array}{c}\text { Equipment } \\
\text { life }\end{array}$ \\
\hline WT & 49.5088 & 0.1912 & - & 20 \\
\hline PV & 0.4466 & 0.0013 & - & 20 \\
\hline ES & 0.1276 & 0.0013 & 0.1148 & 20 \\
\hline
\end{tabular}

Figure 2 is a typical daily load curve for the area. Figure 3 shows typical meteorological data at the location of the microgrid.

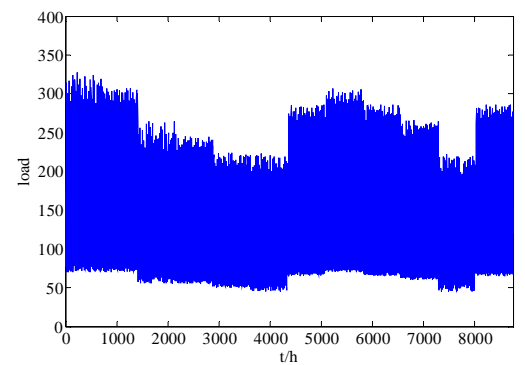

FIGURE II. TYPICAL DAILY LOAD CURVE FOR THE AREA

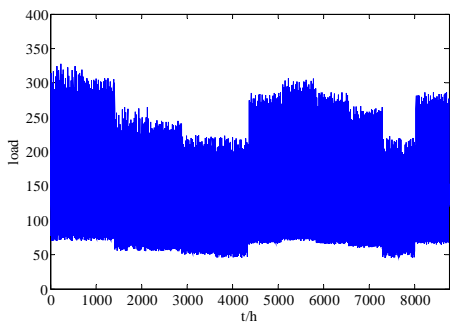

3.1 TYPICAL ANNUAL WIND SPEED DATA

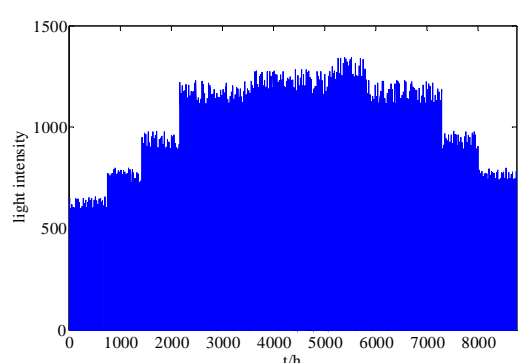

3.2 TYPICAL ANNUAL LIGHT INTENSITY DATA

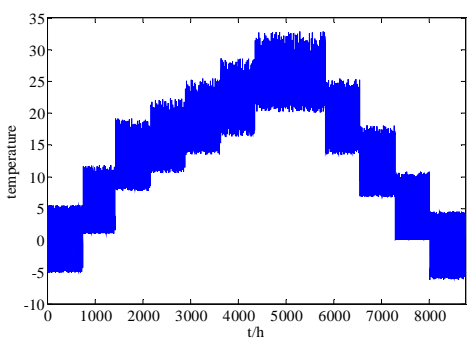

3.3 TYPICAL ANNUAL TEMPERATURE DATA

FIGURE III. TYPICAL METEOROLOGICAL DATA FOR THE LOCATION OF THE MICROGRID
When the shortage rate is set to $1 \%$, the simulation result data is shown in Table 2.

TABLE II. SIMULATION RESULT WHEN THE LPSP IS 1\%

\begin{tabular}{|c|c|c|c|c|c|c|}
\hline $\begin{array}{c}\text { algorit } \\
\text { hm }\end{array}$ & $\begin{array}{c}\text { W } \\
\mathbf{T}\end{array}$ & $\begin{array}{c}\mathbf{P} \\
\mathbf{V}\end{array}$ & $\mathbf{E S}$ & $\begin{array}{c}\text { LPS } \\
\mathbf{P}\end{array}$ & EXC & ACS \\
\hline PSO & 10 & 10 & 30 & 0.01 & 0.284 & 98.28 \\
& & 00 & 8 & & 77 & 62 \\
\hline IPSO & 10 & 10 & 28 & 0.01 & 0.276 & 95.07 \\
& & 00 & 6 & & 57 & 95 \\
& & & & & & \\
\hline
\end{tabular}

When the shortage rate is set to $2 \%$, the simulation result data is shown in Table 3.

TABLE III. SimULATION RESULT WHEN THE LPSP IS 2\%

\begin{tabular}{|c|c|c|c|c|c|c|}
\hline $\begin{array}{c}\text { algorith } \\
\mathbf{m}\end{array}$ & $\begin{array}{c}\text { W } \\
\text { T }\end{array}$ & PV & ES & $\begin{array}{c}\text { LPS } \\
\mathbf{P}\end{array}$ & EXC & ACS \\
\hline PSO & 9 & 10 & 26 & 0.02 & 0.2400 & 90.968 \\
& & 00 & 8 & & 8 & 4 \\
\hline IPSO & 9 & 10 & 26 & 0.02 & 0.2365 & 89.255 \\
& & 00 & 3 & & 7 & 7 \\
\hline
\end{tabular}

When the shortage rate is set to $2 \%$, the simulation result data is shown in Table 3.

TABLE IV. SIMULATION RESUlt WHEN THE LPSP Is 3\%

\begin{tabular}{|c|c|c|c|c|c|c|}
\hline $\begin{array}{c}\text { algorith } \\
\mathbf{m}\end{array}$ & $\begin{array}{c}\text { W } \\
\mathbf{T}\end{array}$ & PV & ES & $\begin{array}{c}\text { LPS } \\
\mathbf{P}\end{array}$ & EXC & ACS \\
\hline PSO & 9 & 10 & 24 & 0.03 & 0.218 & 85.86 \\
& & 00 & 0 & & 84 & 6 \\
& & & & & & \\
\hline IPSO & 9 & 10 & 23 & 0.03 & 0.193 & 84.46 \\
& & 00 & 8 & & 75 & 08 \\
& & & & & & \\
\hline
\end{tabular}

Figure 4 shows the convergence curves of the two algorithms when the LPSP is set to $2 \%$.

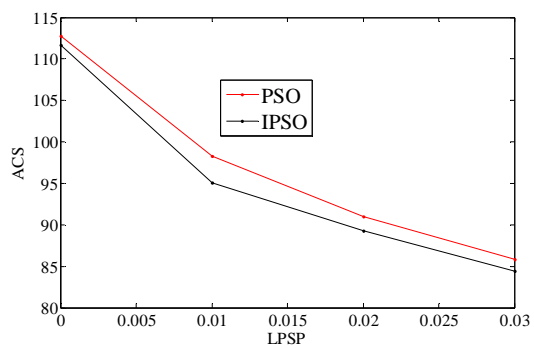

FIGURE IV. COMPARISON OF THE RESULTS OF THE TWO ALGORITHMS BETWEEN IPSO AND PSO

Figure 5 is the relationship between the loss of power supply probability and the annualized cost of the system. 


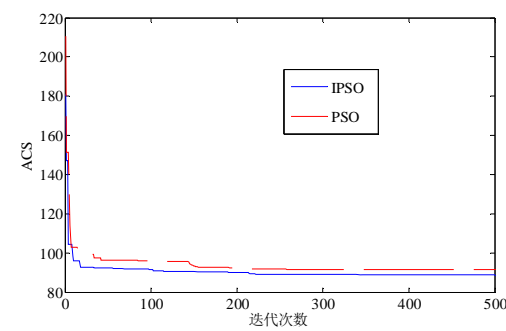

FIGURE V. RELATIONSHIP BETWEEN LPSP AND ACS

The simulation results show that the annualized cost of the improved particle swarm optimization algorithm was obviously lower than the basic particle swarm optimization algorithm. The convergence speed is faster and overcome disadvantages of the general particle swarm optimization. And the convergence is not reliable when the number of iterations is less. Besides, the energy excess ratio is smaller under the improved particle swarm optimization algorithm. As can be seen from figure 5, the larger the power deficit, the lower the annual investment cost. Thus it can be seen that reasonable assessment of the loss of power supply probability is one of the effective means to reduce the redundant investment of microgrid power supply.

\section{CONCLUSION}

The paper optimizes the micro power supply in the ac/dc hybrid micro-grid. The cost of power installation, operation maintenance and equipment replacement is considered, as well as the loss of power supply probability and energy excess ratio. In the matlab software simulation platform, the improved particle swarm optimization algorithm and the basic particle swarm optimization algorithm are simulated, and the simulation examples are compared and analyzed. The results show that the improved particle swarm algorithm can effectively save the cost of the system, and it is very important to improve the economy of the hybrid micro-grid.

\section{ACKNOWLEDGMENT}

The paper was financially supported by the National Natural Fund Project of China under Grant 51567016. The author gratefully acknowledges this financial support and the guidance of tutor.

\section{REFERENCES}

[1] Wang P, Liu X, Jin C, et al. A hybrid AC/DC micro-grid architecture, operation and control[C]. Power and Energy Society General Meeting. IEEE, 2011: 1-8J. Clerk Maxwell, A Treatise on Electricity and Magnetism, 3rd ed., vol. 2. Oxford: Clarendon, 1892, pp.68-73.

[2] Hosseinzadeh M, Salmasi F R. Robust Optimal Power Management System for a Hybrid AC/DC Micro-Grid[J]. IEEE Transactions on Sustainable Energy, 2015, 6(3):675-687.

[3] Unamuno E, Barrena J A. Hybrid AC/DC Microgrids-Part II: Review and classification of control strategies[J]. Renewable \& Sustainable Energy Reviews, 2015, 52: 1123-1134.

[4] ZHU Yongqiang, JIA Lihu, CAI Bingqian, et al. Overview on topologies and basic control strategies for hybrid AC/DC microgrid[J]. High Voltage Engineering, 2016, 42(9): 2756-2767.

[5] LU Jingling, CHENG Xiaoyue, XU Chao, ZAHNG Qiang. Optimal sitting and sizing of distributed generation planning in a standalone micro-grid considering low-carbon economy[J]. Journal of North China Electric Power University(Natural Science Edition), 2014, 41(04): 61-68.

[6] Vallem M R, Mitra J. Siting and sizing of distributed generation for optimal microgrid architecture[C]. Power Symposium, 2005 Proceedings of the, North American. IEEE, 2005:611-616.

[7] Lu Yang, Lu Jinling, Shi Shao-tong, et al. Optimal siting and sizing of distributed generation planning in microgrid by considering stochastic characteristic[J]. Proceedings of the CSU-EP-SA, 2013, 25(3): 108-114.

[8] Lu Jinling, Cheng Xiaoyue, Xu Chao, Zhang Qiang. Optimal configuration of power source in micro-grid system integrated wind and pv power[J]. Acta Energiae Solaris Sinica, 2016, 37(04): 1030-1036.

[9] Fu Yang, Jiang Yiliu, Li ZhenKun. Optimal allocation of distributed generation for microgrid based on hybrid quantum genetic algorithm[J]. Power System Protection and Control, 2013, 41(24): 50-57.

[10] LU Zhilin, WANG Xianqi, TAN Ying Optimal allocation of power supply of grid-connected microgrid using improved biogeography-based optimization algorithm[J]. Proceedings of the CSU-EP-SA, 2017, 29(06) 35-44.

[11] WANG Chengshan, ZHENG Haifeng, XIE Yinghua, et al. Probabilistic power flow containing distributed generation in distribution system[J]. Automation of Electric Power Systems, 2005, 29(24): 39-44.

[12] SHI Qingjun, JIANG Quanyuan. Real-time optimal energy dispatch for microgrid with battery storage[J]. Electric Power Automation Euipment, 2013, 33(05): 76-82.

[13] Hakimi S M, Tafreshi S M M, Kashefi A. Unit sizing of a stand-alone hybrid power system using particle swarm optimization (PSO)[C] . IEEE International Conference on Automation and Logistics. IEEE, 2007: 3107-3112.

[14] Li Dengfeng, XIE Kaigui, HU Bo, et al. Optimal configuration of microgrid power supply based on maximizing net benefits[J] . Power System Protection and Control, 2013, 41(20): 0-26.

[15] Ohatkar S N, Bormane D S. Hybrid channel allocation in cellular network based on genetic algorithm and particle swarm optimisation methods[J]. Iet Communications, 2016, 10(13):1571-1578.

[16] JIANG Quanyuan, SHI Qingjun, LI Xingpeng, et al. Optimal configuration of standalone wind-solar-storage power supply system[J]. Electric Power Automation Euipment, 2013, 33(7): 19-26.

[17] Tong L, Li X, Hu J, et al. A PSO Optimization Scale-Transformation Stochastic-Resonance Algorithm with Stability Mutation Operator[J]. IEEE Access, PP(99):1-1. 